\title{
An Ontology-Based Modelling of Vietnamese Traditional Dances
}

\author{
Truong-Thanh $\mathrm{Ma}^{1}$, Salem Benferhat ${ }^{2}$, Zied Bouraoui $^{2}$, Karim Tabia ${ }^{2}$, Thanh-Nghi Do ${ }^{1}$, Huu-Hoa Nguyen ${ }^{1}$ \\ ${ }^{1}$ CICT, Can Tho University, Vietnam \\ Email: truongthanh1511@gmail.com \\ \{dtnghi,nhhoa\}@ cit.ctu.edu.vn \\ 2 CRIL, Artois University \\ CRIL CNRS \& Univ Artois, France \\ Email:\{benferhat, bouraoui, tabia\}@cril.fr
}

\begin{abstract}
Ontology is an essential resource to enhance the performance of information processing system as well as is an intelligent storage area served for management of largescale heterogeneous digital contents resulting. In this paper, we propose the initial steps for reconstructing a significant schema of Vietnamese traditional dances. Most of the typical dances of Vietnamese community are recorded in multimedia format, in raw videos. Accordingly, we concentrated on analyzing and collecting knowledge of the dance experts at art schools in Vietnam to classify and to determine the primary features that would be stored in the ontology. We propose an ontologybased modelling for the cultural heritage domain of Vietnamese traditional dance.
\end{abstract}

Keywords: Vietnamese Traditional Dance, Ontology, Knowledge Representation, Modelling.

\section{INTRODUCTION}

Southeast Asia is one of the most assertive growing regions in the world with natural and cultural resources. Specially, the cultural foundation regarding dance domain plays an important role in community life, it always brings the historical and cultural knowledge to the adjacent generation [1] [11]. The intangible culture heritages (ICHs) of the ethnic group dance are quite difficult to identify the exact values and great significance. This paper focuses on Vietnamese traditional dances (VTDs) which are truthfully assertive and original.

VTDs principally concentrate on four primary aspects: [4][?]: firstly, depicting straightforward the scene of animated daily activities as well as redrawing a picture about traditional careers, particular symbols and outstanding stories in history through truthful dance movements; Secondly, utilizing conventional and ordinary props combined with gentle music. The selected props for performing depend on the song lyric contents in order to express characteristic emotions. The third point is the dance must approach so-called "the true, the good and the beautiful". Vietnamese typical stories and scenes always reflect comprehensively and evidently the daily life of each ethnic group through distinctive dances. The final aspect is the dance message. Most of the VTDs are not only creating aestheticism on the stage as well as serve the entertainment but also transhipping many meaningful messages to audiences.

One of the main contribution of this paper is to propose an ontology-based modelling of VTD. Our ontology is modeled using from the books [1] [4] [10] [11] [2] and also from the dance experts at the art schools in Vietnam. Ontology is a principle of any system to represent knowledge for a given domain [12]. It represents information from multiple heterogeneous sources in concepts and semantic relations of the concepts. Ontology plays an important role in the representation of information processing system and also is one of the formalism of describing entities, the properties and relationship. It also offers to managing and sharing information. Especially, it brings a mission of transhipping information from multimedia data (such as raw video/images) to computer. Correspondingly, utilizing ontology for preserving ICH is a completely appropriate selection because the traditional dances is recorded in raw videos which are complicated and enigmatic for storing heterogeneous information blocks. The combination between artificial intelligence and expert knowledge regarding dance domain for preserving ICH is definitely expected.

Maintaining the intangible cultural properties as well as the traditional dance is extremely difficult. Indeed, the dance documents in Vietnam is extremely limited. Most of the minority ethnic group dances are not written in any book or any document. They retransmitted through "word of mount" form, particularly, the VTDs of minority ethnic groups.

Our VTD approach is decomposed in three primary stages: the first aspect is panorama overview of dances (1); the second angle is region-zone of dances (2), considering this aspect because most of the VTDs depart from distinguishable ethnic groups living region-zone in Vietnam territory; the last approach is the fundamental movements of ethnic groups (3). In this paper, we concentrate on presenting the first stage to build VTD ontology. Our primary challenge is to determine primary concepts combined with essential properties based on expert knowledge and restructuring the ambiguity in VTDs.

The remainder of this paper is structured as follows. In the next section we give an overview and related works. In section 3 , we present expert knowledge to develop ontology for VTDs. In section 4, we discuss and illustrate building an ontology. Finally, section 5 concludes the paper.

\section{OVERVIEW AND RELATED WORKS}

\section{A. Vietnamese Traditional Dance Overview}

Vietnam has a rich cultural heritage, where music and dance has been interwoven with the social fabric. Vietnamese classi- 
cal music and dance portray human emotions, love and devotion, narrate stories from life activities, history and religious and are the integral parts of the festivals and celebrations. List of ICHs compiled by UNESCO includes many dances, instruments, theater and music forms, namely "Đờn ca tài tử" of the Vietnam's South, "Nhã nhạc cung đình" of Huế, "Ca trù" of the Vietnam's North, "Cồng chiên Tây Nguyên" of Western Highlands of Vietnam and so on. Although the VTDs of ethnic groups have not been written into the UNESCO list yet, nevertheless it brings many local traditional cultural values in each particular dance and acknowledged the ICHs in the heart of Vietnamese community.

There are three basic characteristics that the choreographer as well as performer must be paid special attention to: (1) ethnicity, (2) transhipping meaningful message, and (3) "chânthiện-mỹ" (the true, the good and the beautiful). The explicit explanation as follows: firstly, regarding the ethnicity, most dances of the minority ethnic groups is to predominantly concentrate on the ethnicity, in spite of performing with simple movements, they always bring private ethnic features for each performance, it can be local particular props or ethnic costumes. Secondly, considering dance messages, the VTDs is kept in a significant mission to be transhipped at least one message to receivers who is not only spectator but also anything and even be the god. Hence, the VTDs is a steady bridge in educating about human dignity, morality and even historical knowledge. Instead of learning the historical lesson in regular classes as well as participating in the training course for life skills, the dances has become the digital channel for efficient educating personality, knowledge and even ethnicity to the generations. Thirdly, the explanation as follows "chân (the true)" means the performer must express their emotions truthfully inside each movements and face's expression; "thiện (the good)" means the dances approach the best of the activities in life, it brings an aspiration for the bright future of their ethnic group; "mỹ (the beautiful)" means the dances and dancers must be interested in aestheticism.

In addition, Vietnam is a multi-ethnic country bringing many different cultures [11], fifty-four-ethnic groups are living in a territory with many typical multiform dances. The most remarkable feature to easily distinguish the dances of each ethnic group is the ethnic props as well as ethnic traditional costumes. Normally, the ethnic people would wear the private costumes and typical props of their ethnic group for performing in the particular festivals or traditional celebrations. Props as bamboo, hat, towel, soft silk and even daily tools for working as shovel, "lưỡi hái" and baskets are utilized in VTD. Besides we are also seen some ethnic props as "Đàn tính", "khèn" (music instrument), or "Khăn piêu" (handkerchief of Thai people). Almost all ethnic groups possess the private specific costumes of their ethnic group, the selection of the traditional costumes is always the first precedence. Additionally, we are also effortless to catch sight of pastoral pictures through common props as banana tree, bamboo tree, stack of straw for Vietnamese countryside. Generally, most of the VTDs concentrates on rural area than urban region, therefore the scenes and props are utilized to intimately related to countryside or village.

\section{B. Related Works}

The author in [6] illustrates preserving and promoting of intangible cultural through Benesh notation to define the movements, after that using OWL (Ontology web language) and the semantics of Benesh Movement notation (BMN) to build Ontology for video movement. In [5], dances were described and stored taking advantage of expressivity of description logics. Dance choreographies was built in OWL to represent and archive. Besides using SPARQL queries for searching within the ontology based on steps and movements of dances. Another approach for automatic annotation and retrieval of video content, which is based on ontologies, has been presented by Ballan et al [9]. They build an ontology schema based on abstract concepts and relations, after that they described a web video search engine that based on ontologies. In [7], the author group presented a method to encode and structure metadata of folk song collections. This method uses and extends the CIDOC (Conceptual Reference Model) CRM, the research result is to determine the roles and classes provided by CIDOC CRM have been useful in dealing with the particularities of Basque folk song collections.

\section{VTD EXPERT KNOWLEDGE}

\section{A. Expert Knowledge Congregation}

VTD is the art form reflecting the human life through its formal form, most of the gestures and movements intimately related to processing manual labor as well as the life activities in ethnic community. Each dance performance session lasts from 4 minutes to 10 minutes, including average about 5-10 dancers (normally) [11]. In VTD, it splits two types: "múa dân gian" (folk dance or community dance) and "múa cung đình" (court dance or dance in theatre). They are known as "Múa dân tộc", we could call traditional dance in English. In this section, we concentrate primarily to explicitly model the knowledge on VTD, which could be split in five categories: non-story dances (dư-hứng), bare-handed traditional dances of Vietnam, historical dances, dances about traditional manual labor of ethnic groups, dances in festival and daily life.

The following details each of these categories:

1) Non-story dances - (du-húng): In Vietnam, non-story dance is one of the most prevalent dance forms that the ethnic group utilizes to perform in life as well as in the significant events. "Dư Hứng dance" is the common name of this dance form which is called by experts of the dance domain. These dances are the performances without story. The remarkable feature of these dances is the ethnicity and community, because the dance performance brings a private ethnic color in each particular movement. The performers could play creatively in anywhere and any kind of music. Non-story dances are divided in two main kinds as in sub-schema of Figure 1 do that: utilizing props for performing and dances without props (bare-handed dance). 
In this subsection, we concentrate on analyzing the dances utilizing props without plot. Normally, the props intimately related to life activities and typical ethnic group symbols. Considering about props of life, there are four main props: (1) flowers, (2) manual labor tools, (3) instruments and (4) symbols. Firstly, most of the flowers would be one of the first selection in VTDs, there are many kinds of flower for performing as lotus dance, sunflower dance, rose dance and so on. In which, lotus and sunflower is performed the most because they had been acknowledged as national flower by Vietnamese community. Secondly, the manual labor tools is also performed in dances, it is the tools of the life activities, for example: "pick tea leaves" dance of Thai ethnic group with familiar prop "gùi - similar with papoose" or "Lên nương dance" with hoe tool and leaf-hat. Thirdly, the ethnic instruments are also the dance name and they would be primary props to perform in those dances, namely "Đàn tính" dance (a kind of instrument of Thái ethnic group), "Trống Cơm" dance (a kind of drum), "gong" dance (percussion instrument) and so on. Finally, the local and national symbols also performed in the major festival of ethnic groups, including lotus dance, "trống đồng" dance.

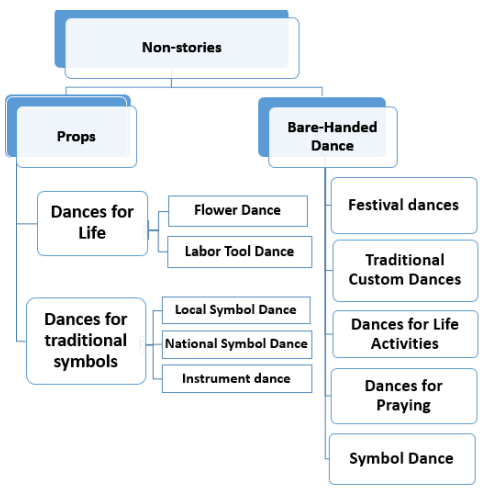

Figure 1. Sub-schema of non-story dances

2) Bare-handed dances: This is the dances that performers just utilize the hands and body language without any prop in each dance performance. Creating the distinct hand gestures combine the fundamental movements is one of the private features of these dances. Normally, the dance performances are organized from two to eight people for a dance formation, sometimes even there are the large number of dancers participated in this dance group. There are five main subjects in these dances: (1) symbol dances without props, (2) traditional custom dances, (3) dances for life activities , (4) festival dances, (5) dances for praying. The following details each of the five subjects in bare-handed dances: Firstly, this is dance that performer using body-language to depict ethnic symbols. Instead of utilizing props for performing, these dance performances would be imaginableness through postures and movements, evidence as lotus dance, peafowl dance (note that do not must forms of shadow dance). Secondly, the dances about traditional custom is performed in remarkable events of ethnic groups or anniversaries, such as "Xòe-thương-nhau" dance, HMông dance. Thirdly, the dances for life activities is performed at parties (wedding, birthday) in ethnic community (note that it is not as formal as traditional custom dances), example as Lăm-leo dance, dù-kê dance of Khmer ethnic group. Fourthly, the remarkable feature of festival dances is heightened the ethnicity in each dance performances. Normally, the circle formation in festival with simple movements to create funny atmosphere is always selected to perform, such as rom-vong dance, saravan dance and so on. Finally, let us consider [10] an example regarding "Tắc-xình" dance of "SánChay" ethnic group is an evidence for praying in dances. This dance is in "cầu mùa" (pray for harvest) festival, it is not only bringing wishes of the good harvest but also an aspiration for connecting the communities together.

3) Historical dances: The historical dance performance depicted the scenes of the outstanding events of Vietnamese history as well as the legends. We could split historical dances on three primary aspects: Firstly, the scene of remarkable war events (1), such as "The great victory on the spring in 1975", "The Dien Bien Phu victory"; Secondly, the scene of an illustrious national hero (2) had batted unyieldingly in antitrespassing wars as well as the prominent background of national hero, such as sister "Võ Thị Sáu", Uncle Ho, Vương king; and the third aspect (3) is the legends of Vietnam, as "Lac Long Quan" king an AuCo Queen, "Thánh gióng".

Generally, most of the dance performances primarily concentrates on the historical message transhipping, the noticeable point is the selected props for performance to be inherent in the historical figure, example: dragon boat and magic sword associate with "Lê Lợi" King; Rằn handkerchief and Áo-bà-ba (Skirt) associate with "Võ Thị Sáu". The remarkable feature of these dances is the personality description as well as transhipping the content of story. The choreographers must select the cardinal features of story to build dance lesson, through the meaningful stories will be worth lessons to recommend and to educate the present generation regarding moral person, history and ethnicity.

4) Dances regarding traditional manual labor: The dance performances regarding traditional labor is necessary with supporting of props and bringing a plot. The dances depict truthfully the scenes of traditional manual works. It could be the steps as well as the stages on the process of traditional manual labor in their ethnic group. Normally, the choreographer extracts the scene from the traditional works to build the dance performance, they would retrace step-by-step of the scenes in their traditional career to aim at honoring the labor values. For examples: the salt village dance - they would perform their traditional work with four segments (getting water from sea, containing water, drying-water, crystallizing).

5) Dances in festival and daily life: In Vietnam, the dances regarding daily life is split in two main kinds: the dances in rural (1) and the dances in urban (2). Dances for rural region depicts the scene of countryside, works on the fields and even the scenes from daily life activities with pasturing buffaloes, fishing and cultivation. In contract, considering 


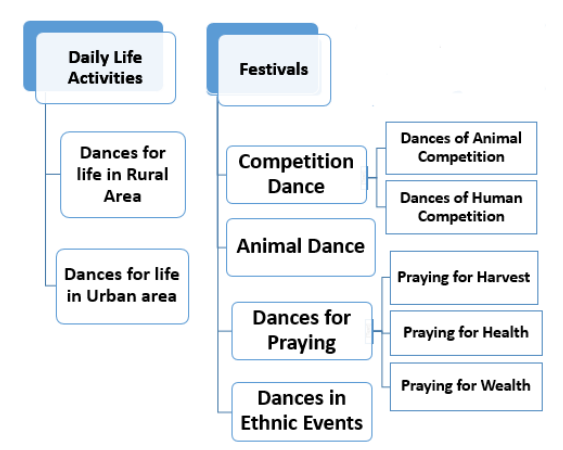

Figure 2. The sub-schema of festival dances and daily life dances

dances for urban areas is the scenes of the modern life to reflect the bad activities from the young generation. It extracts the dark background in the city to admonish their children (the adjacent generations). More importantly, almost all the dances regarding life of urban area is belonged to Kinh ethnic group.

On the other hand, considering the dances in festival, it splitted on four particular aspects as in Figure 2 the first aspect is animal dance (1). The second one is competition dances between human and animal (2). Thirdly is the dances in significant event (3); and last aspect is the dances for praying (4). All dances in this section always bring a plot in each dance performance. Firstly, considering animal dances, normally, this animal is treasured in the ethnic community, such as: "tortoise dance" of Dao ethnic group. These animal dances would like to receive lucky, happiness and prosperity from sacred animal. Secondly, regarding competition dance, this is the dance performance relevant to competition between animals together or between animal and human. Generally, these dances focus on taming the bad character to return with good lifestyle. Thirdly, the dances in event, it is the special traditional dances to welcome visitor in significant events. These events could be the annual events, the new outstanding events and ethnic community events without bringing the historical elements. In last aspect, regarding praying in dance [10], these dances praying about harvesting the good crops in the whole year or praying for sufficient money, food and happiness or praying a good health for all members in their family and village.

\section{B. Structure of Vietnamese Traditional Dances}

This subsection provides a brief overview schema for VTD. We recall that this schema is based on [1] [4] [10] [11] but also benefits from the dance experts (consist of dance choreographers, dancers and their teacher) at art school in Vietnam, we have selected the significant features to reconstruct the schema for VTD regarding case of the panorama overview as Figure 3 There are three main features that the dance experts have suggested to be interested in researching: Firstly, ethnicity in dances to answer for question about "ethnic groups" because most of the traditional dances depart from the customs of ethnic groups, interested in props and costumes. Secondly,

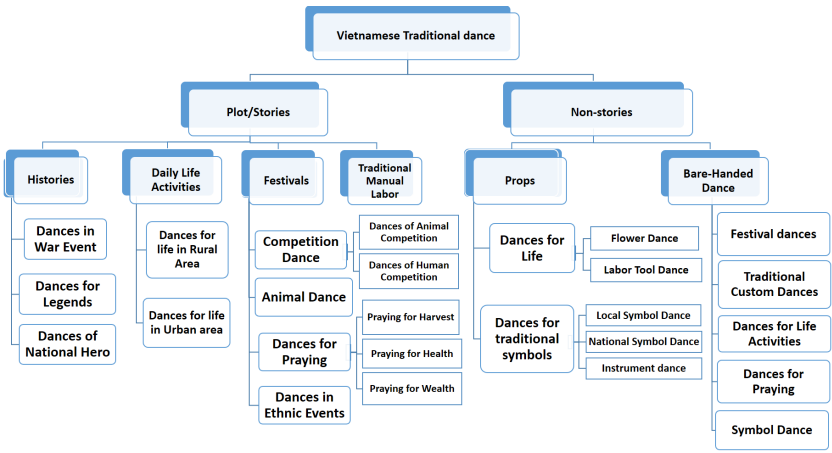

Figure 3. The overview schema for VTD

transhipping the meaningful messages to spectator, interested in plot. Thirdly, festivals or events of ethnic groups.

IV. CONCLUSion AND Future Works

The preservation and promotion of ICH is one of the most interest and worried problems in Vietnamese community, particularly, in case of traditional dances. For preservative purpose, we collected significant features needed to build an ontology for VTD. The work presented in this paper is the first stage regarding preserving and promotion of VTDs based upon the background of artificial intelligent. Our next plans include enhancement and extension of the VTD ontology following different aspects and concentrate on developing applications automatically based on ontology.

\section{ACKNOWLEDGEMENTS}

This work has received support from the European Project H2020 Marie Sklodowska-Curie Actions (MSCA), Research and Innovation Staff Exchange (RISE): Aniage project (High Dimensional Heterogeneous Data based Animation Techniques for Southeast Asian ICH Digital Content), No: 691215.

\section{REFERENCES}

[1] L.T.Loc, "Mua dan gian cac dan toc Viet Nam", in Thoi-dai Publishing house, 1994

[2] T.V. Son, Đ. T. Hoàn, N. T. M. Hương, "Mua dan gian mot so dan toc vung Tay Bac", in Culture and Nation Publishing House, 2003.

[3] J. Davies, A. Duke, Y. Sure, "OntoShare - An Ontology-based Knowledge Sharing System for virtual Communities of Practice", in proceedings of the 28th International Florida Artificial Intelligence Research Society Conference (FLAIRS), 2005.

[4] L.N. Canh, "Nghệ thuật múa Hà Nội truyền thống và hiện đại", in Hà Nội Publishing House, 2011.

[5] E.R. Katerina, I. Yannis, "A labanotation based ontology for representing dance movement", in Proceedings of the 9th Int Gesture Workshop, 2011.

[6] S. Sawsan, D.B. Dominique, M. Said, M.Pierre, "An ontology for video human movement representation based on Benesh notation", in Proceedings of Multimedia Computing and Systems (ICMCS), 2012.

[7] S. Debastian. "Ontologies for representation of folk song metadata", in Technical report, EHKZAARE201201, 2012.

[8] S.Renzo and A. Hernan, "Ontology and semantic wiki for an ICH inventory", in Proceedings of Computing Conference (CLEI), 2013.

[9] L. Ballan, A. Del Bimbo and G. Serra, "Learning Ontology Rules for Semantic Video Annotation", in Proceedings of the 2nd ACM workshop on Multi semantics, 2008

[10] L.N.Canh. "Múa tín ngưỡng dân gian Việt Nam", in Social Science Publishing house, 1998.

[11] L.N.Canh. "Đại cương nghệ thuật múa", in Culture and information publishing house, 2003. 